\title{
B7-H3 expression in ductal and lobular breast cancer and its association with IL-10
}

\author{
CHUANYONG LIU ${ }^{1 *}$, JIE LIU $^{1 *}$, JIE WANG $^{2}$, YAN LIU $^{3}$, FANG ZHANG $^{4}$, WENLI LIN $^{1}$, \\ AIQIN GAO ${ }^{1}$, MEILI SUN ${ }^{1}$, YUNSHAN WANG ${ }^{3}$ and YUPING SUN ${ }^{1}$ \\ Departments of ${ }^{1}$ Oncology and ${ }^{2}$ General Surgery; ${ }^{3}$ Medical Diagnosis Laboratory; ${ }^{4}$ Department of Pharmacy, \\ Jinan Central Hospital, Affiliated to Shandong University, Jinan, Shandong 250013, P.R. China
}

Received June 6, 2012; Accepted September 20, 2012

DOI: $10.3892 / \mathrm{mmr} .2012 .1158$

\begin{abstract}
Aberrant tumor cell expression of B7-H3, a member of the B7-family that stimulates interleukin-10 (IL-10) secretion, contributes to tumor immune evasion and tumor progression. The aim of this study was to investigate the expression of B7-H3 and IL-10 in ductal and lobular breast cancer tissues. Using immunohistochemistry, B7-H3 and IL-10 protein expression in tumor specimens of primary human breast cancer was investigated. The association between B7-H3 or IL-10 expression and clinicopathological variables was analyzed. The correlation between the expression of B7-H3 and IL-10 was also evaluated. In tumor tissues, the expression of B7-H3 and IL-10 was identified on the cell membrane and in the cytoplasm. Expression of B7-H3 was observed in $90.60 \%$ $(106 / 117)$ of the specimens and $80.34 \%$ (94/117) expressed IL-10. Patients with a positive B7-H3 or high IL-10 expression were more likely to have positive lymph node metastasis (N1-3; $\mathrm{P}=0.018$ or 0.035 , respectively) and advanced disease (stage II-IV; $\mathrm{P}=0.011$ or 0.039 , respectively) compared to those with a negative or low expression. Furthermore, B7-H3 expression was correlated with IL-10 in tumor cells $(\mathrm{R}=0.545$, $\mathrm{P}=0.000)$. High B7-H3 expression in human breast cancer tissues may be important in tumor progression and invasiveness. This expression appeared to be correlated with the ability of B7-H3 to promote IL-10 secretion.
\end{abstract}

Correspondence to: Professor Yuping Sun, Department of Oncology, Jinan Central Hospital Affiliated to Shandong University, 105 Jie Fang Road, Jinan, Shandong 250013, P.R. China

E-mail: sunyuping@live.cn

Professor Yunshan Wang, Medical Diagnosis Laboratory, Jinan Central Hospital Affiliated to Shandong University, 105 Jie Fang Road, Jinan, Shandong 250013, P.R. China

E-mail: sdjnwys@163.com

${ }^{*}$ Contributed equally

Key words: B7-H3, immunohistochemistry, breast cancer, interleukin-10

\section{Introduction}

Breast cancer is one of the most common female malignancies. Despite the use of a wide range of adjuvant treatment options, including radiotherapy, conventional chemotherapy with cytotoxic antitumor agents alone or in combination with endocrine therapy, bisphosphonates and HER-2/neu-directed therapy, over 400,000 females are predicted to succumb to breast cancer worldwide each year (1). Thus, new therapeutic strategies for breast cancer should be identified where viable treatment options are not successful.

A defect in the immune response may contribute to tumor growth. T-cell co-stimulation is essential for the initiation of an immune response. Lack of expression of CD80 and CD86 on tumor cells is considered to be one reason for immune evasion $(2,3)$. However, inhibitory co-stimulatory factors may be involved in the pathogenesis by inducing T-cell anergy in two ways: inducing inhibitory cofactor expression in effector immune cells or expression of ligands of inhibitory cofactors on tumor cells. Blocking the interaction of inhibitory cofactors is a new strategy in tumor therapy. Therefore, manipulation of inhibitory costimulatory molecules may be critical for the control of an immune response.

The $\mathrm{B} 7$ protein family provides stimulatory and inhibitory regulation of T-cell responses, depending on which $\mathrm{B} 7$ ligand or receptor is engaged on the target $(4,5)$. B7-H3 is a previously identified member of the B7 family. It was initially identified as a co-stimulatory molecule. However, studies suggest a role of B7-H3 in the inhibition of T-cell response (6-8). Ling et al (8) demonstrated that immunoglobulin-V-like and immunoglobulin-C-like (VC) and VCVC forms of human B7-H3 inhibited $\mathrm{CD}^{+}{ }^{+} \mathrm{T}$-cell proliferation and downregulated cytokine production upon TCR activation in vitro. Using B7-H3-deficient mice, Prasad et al (6) demonstrated an enhanced lung inflammatory infiltration by macrophages and lymphocytes. B7-H3 mRNA, but not protein expression, was detected in a wide range of normal somatic tissues $(9,10)$. However, expression of the cell surface B7-H3 may be induced on monocytes and dentritic cells (DCs) by interferon- $\gamma(9)$.

B7-H3 protein has modest biological activities associated with T-lymphocyte proliferation and enhanced interleukin-10 (IL-10) secretion (11). IL-10 is a multifunctional cytokine and has marked immunosuppressive effects $(12,13)$. 
In breast cancer patients, IL-10 has been reported to be overexpressed in sentinel lymph nodes of breast cancer and associated with specific tumor markers of poor prognosis $(14,15)$. However, it is currently unclear whether IL-10 production by tumor cells is relevant to the tumor-associated B7-H3 expression.

To gain insight into the mechanism of breast cancer progression, this study examined the expression of B7-H3 and IL-10 in ductal and lobular breast cancer specimens. The association between B7-H3 or IL-10 expression and clinicopathological characteristics was then analyzed. To explore the possible mechanism underlying this association, the correlation between B7-H3 and IL-10 in tumor cells was also investigated.

\section{Materials and methods}

Patient characteristics. Tumor specimens were obtained from 117 patients with primary breast cancer who underwent surgery at the Clinical Hospital of Shandong University (Shandong, China) between 2008 and 2010. The mean age of patients at the time of diagnosis was 51 years (range, 21-77). There were 97 invasive ductal and 20 lobular carcinomas. Patients were classified as American Joint Committee on Cancer pathological stage I (33 cases), stage II (52 cases) or stage III (32 cases). All patients provided written informed consent for the use of specimens and the study was approved by the Institutional Review Board.

Information on estrogen receptor (ER), progesterone receptor (PR) and human epidermal growth factor receptor 2 (HER-2/neu) status was collected from original surgical pathological reports and records of surgery, in-patient medical records, chest X-ray films, whole-body computed tomography (CT) films and bone scanning films were also reviewed.

Immunohistochemistry. Immunohistochemical staining was performed using the biotin-streptavidin-peroxidase method with a Vectastain ABC kit (Vector Laboratories Inc., Burlingame, CA, USA). Resected tissue specimens were fixed in formalin, embedded in paraffin, cut into $4-\mu \mathrm{m}$ serial sections and then mounted on glass slides. Slides were deparaffinized with xylene and dehydrated in graded alcohol. Following this procedure, the antigen was retrieved through heating in a microwave for $2 \mathrm{~min}$ at $900 \mathrm{~W}$ and the antigen was incubated with $0.3 \%$ $\mathrm{H}_{2} \mathrm{O}_{2}$ solution in methanol for $30 \mathrm{~min}$ to block endogenous peroxidase. Slides were then washed three times with PBS and incubated in $10 \%$ normal horse serum to block nonspecific background staining. Sections were incubated with the primary antibodies in a humid chamber at $4^{\circ} \mathrm{C}$ overnight. Mouse antiB7-H3 (diluted 1:60; R\&D Systems, Minneapolis, MN, USA) and anti-IL-10 (diluted 1:100; BiosPacific, Emeryville, CA, USA) were used as primary antibodies. Following additional washing with PBS, sections were incubated with biotinylatedhorse anti-mouse antibodies for $30 \mathrm{~min}$, washed three times with PBS and then incubated with streptavidin-conjugated peroxidase for $30 \mathrm{~min}$. Sections were visualized by incubation with 3,3'-diaminobenzidine solution $(0.3 \%$ hydrogen peroxide and $0.05 \%$ 3,3'-diaminobenzidine) and counterstained with hematoxylin. Negative controls were carried out by substituting a normal mouse IgG for the primary antibody.
B7-H3 and IL-10 expression. Histological analysis was performed simultaneously by two investigators using a doubleheaded light microscope without knowledge of the patients' clinical records. B7-H3 or IL-10 expression was defined as the percentage of tumor cells exhibiting immunoreactivity in the cytoplasm or on the cell membrane and calculated by counting the number of B7-H3- or IL-10-stained tumor cells among 1,000 tumor cells in each section. Cell counts were performed at X400 magnification, in at least 5 fields, in randomly selected tumor areas. The intensity of the positive cells for B7-H3 and IL-10 was also graded semiquantitatively according to the positive cell percentage: 0 , expression $<10 \%$; $+10-40 \%$; ++, $40-80 \% ;+++,>80 \%$. Specimens were classified into two groups based on the staining intensity consisting of a negative group (expression $<10 \%$ ) and a positive group (expression 10-100\%).

Statistical analysis. Correlation between the expression of B7-H3 or IL-10 and clinicopathological variables was analyzed using Fisher's exact or the $\chi^{2}$ test, where appropriate. Spearman correlation coefficient was used to determine the association between B7-H3 and IL-10 expression. $\mathrm{P}<0.05$ was considered to indicate a statistically significant difference. Statistical analyses were performed using SPSS 16.0 (IBM).

\section{Results}

B7-H3 and IL-10 expression in ductal and lobular breast cancer tissue. B7-H3 was expressed in 106 of 117 specimens and IL-10 was expressed in 94 of 117 specimens $(90.60 \%$ and $80.34 \%$, respectively). In the majority of cases the expression pattern of B7-H3 and IL-10 in tumor cells appeared to be extremely diffuse throughout the section. Microscopically, B7-H3 and IL-10 were identified in the tumor cell membrane, cytoplasm, or both (Fig. 1A, C, E and G). Expression of IL-10 was also observed in infiltrating lymphoid cells, while little staining of B7-H3 was identified in the stromal cells. Distribution of the B7-H3 and IL-10 staining intensity in all specimens is demonstrated in Figs. 2 and 3.

Correlation between B7-H3 or IL-10 expression and clinicopathological factor. Table I shows a comparison of the clinical pathological factors with B7-H3 or IL-10 positive and negative expression groups. Patients with positive B7-H3 or high IL-10 expression (focal expression of the staining $\geq 40 \%$ ) were more likely to have lymph node metastasis $(\mathrm{P}=0.018$ for $\mathrm{B} 7-\mathrm{H} 3$ and $\mathrm{P}=0.035$ for IL-10) and advanced disease (stage II-IV; $\mathrm{P}=0.011$ for $\mathrm{B} 7-\mathrm{H} 3$ and $\mathrm{P}=0.039$ for IL-10) compared to those with negative $\mathrm{B} 7-\mathrm{H} 3$ or low IL-10 expression (focal expression of the staining $<40 \%$ ). IL-10 expression was higher in larger tumors $(>2 \mathrm{~cm})$ and HER-2/neu-positive groups, but did not approach significance. No significant correlation was identified between age, histological types, differentiation, ER or PR status and the expression of B7-H3 or IL-10.

Correlation between the expression of B7-H3 and IL-10. To explore the possible mechanism underlying the association between B7-H3 and tumor progression, we analyzed whether B7-H3 expression was correlated with IL-10 levels. The results indicated a positive correlation between $\mathrm{B} 7-\mathrm{H} 3$ and IL-10 expression $(\mathrm{R}=0.545, \mathrm{P}=0.000)$ (Fig. 4). 

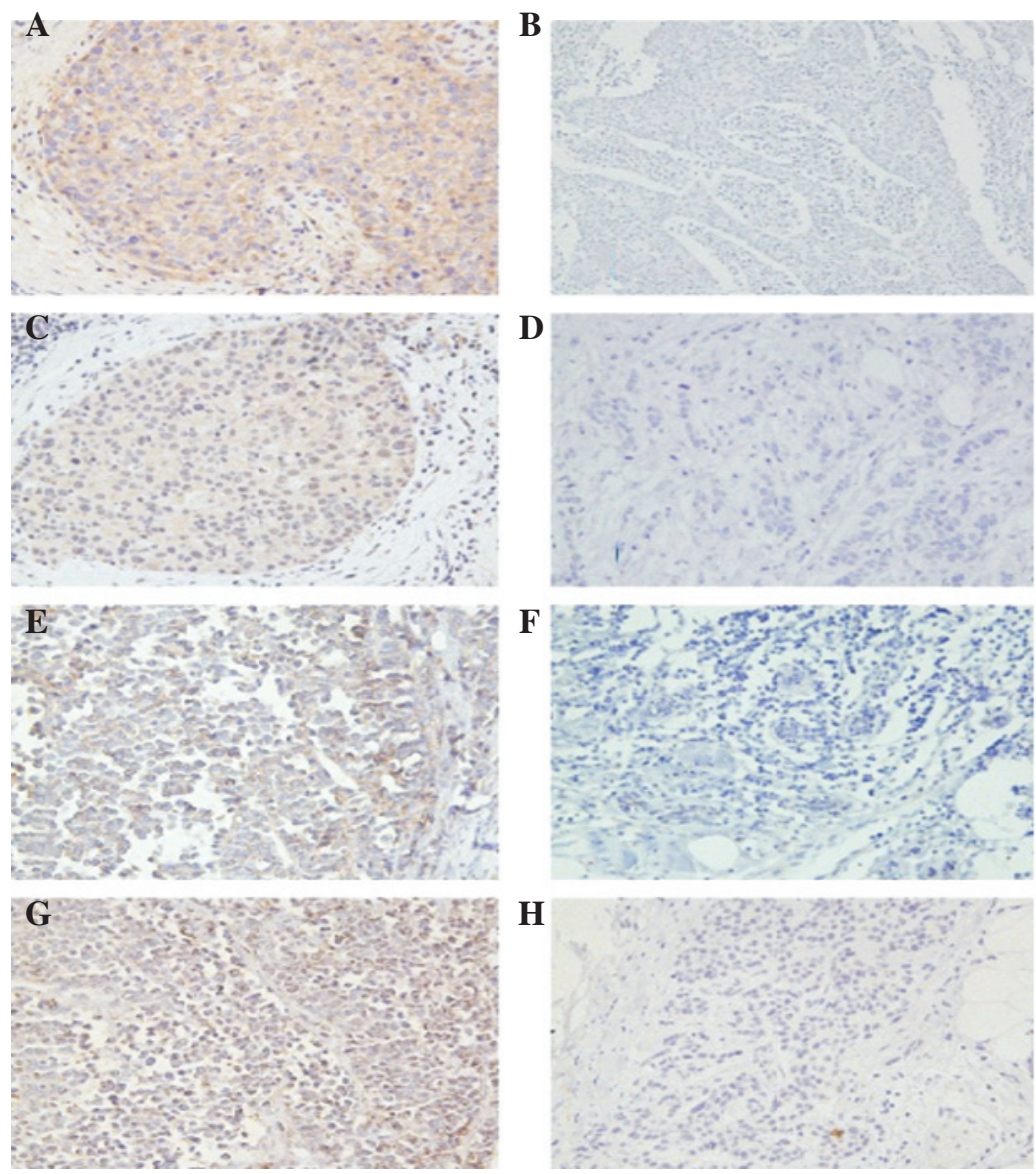

Figure 1. Sections from ductal and lobular breast cancer stained immunohistochemically for B7-H3 and interleukin-10 (IL-10). (A) B7-H3- and (C) IL-10positive cancer cells with grade +++ (original magnification, x200) in ductal breast cancer. (B) B7-H3- and (D) IL-10-negative cancer cells (original magnification, x200) in ductal breast cancer. (E) B7-H3- and (G) IL-10-positive cancer cells with grade +++ (original magnification, x200) in lobular breast cancer. (F) B7-H3- and (H) IL-10-negative cancer cells (original magnification, x200) in lobular breast cancer. IL-10, interleukin-10.

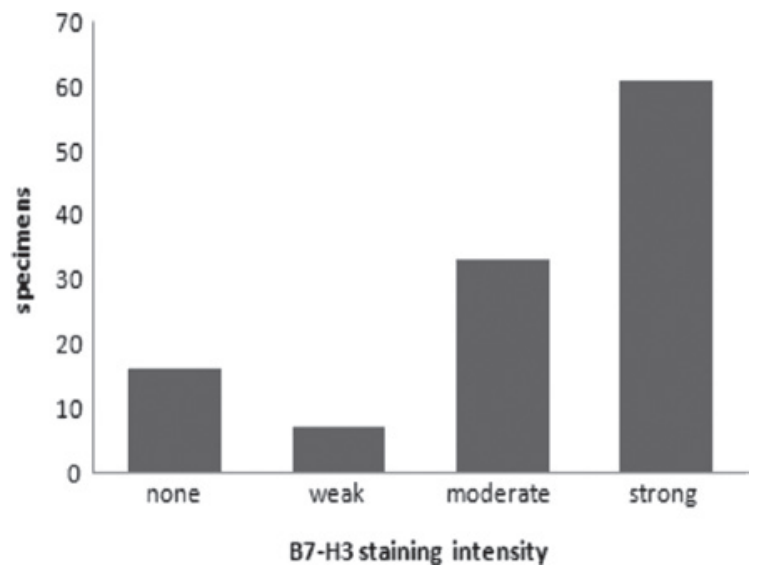

Figure 2. Distribution of B7-H3 staining intensity in ductal and lobular breast cancer tissues.

\section{Discussion}

Numerous therapeutic modalities are available for adjuvant treatment of advanced breast cancer, including radiotherapy, conventional chemotherapy with cytotoxic antitumor agents, hormone therapy and signal-transduction inhibitors (16). However, a number of patients respond poorly to existing

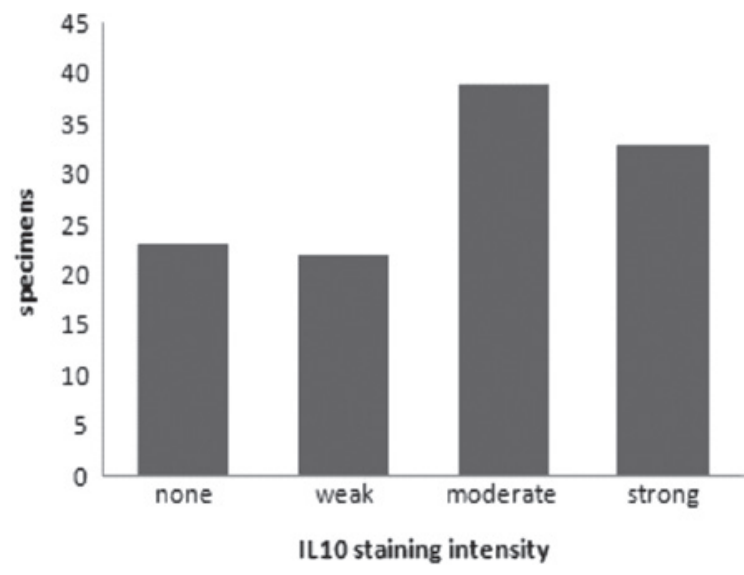

Figure 3. Distribution of interleukin-10 (IL-10) staining intensity in ductal and lobular breast cancer tissues.

therapeutic modalities. Thus, new molecular targets are required for the development of novel therapeutic strategies for the treatment of breast cancer.

B7-H3 is a transmembrane glycoprotein and a member of the B7 family of proteins, previously known as an immunoregulatory molecule, demonstrated to be inducible in macrophages and DCs (6). More recently, it was identified to 
Table I. Correlation between B7-H3 or IL-10 expression in tumor cells and clinicopathological factors.

\begin{tabular}{|c|c|c|c|c|c|c|c|}
\hline \multirow[b]{2}{*}{ Clinicopathological factors } & \multirow[b]{2}{*}{ No. } & \multicolumn{2}{|c|}{ B7-H3 expression } & \multirow[b]{2}{*}{ P-value } & \multicolumn{2}{|c|}{ IL-10 expression } & \multirow[b]{2}{*}{ P-value } \\
\hline & & Positive & Negative & & Positive & Negative & \\
\hline \multicolumn{8}{|l|}{ Age (years) } \\
\hline$\leq 50$ & 63 & 56 & 7 & \multirow[t]{2}{*}{0.543} & 34 & 29 & \multirow[t]{2}{*}{0.854} \\
\hline$>50$ & 54 & 50 & 4 & & 28 & 26 & \\
\hline \multicolumn{8}{|l|}{ Histological cancer types } \\
\hline Ductal & 97 & 89 & 8 & \multirow[t]{2}{*}{0.397} & 53 & 44 & \multirow[t]{2}{*}{0.432} \\
\hline Lobular & 20 & 17 & 3 & & 9 & 11 & \\
\hline \multicolumn{8}{|l|}{ Differentiation } \\
\hline Well & 22 & 19 & 3 & \multirow[t]{2}{*}{0.431} & 10 & 12 & \multirow{2}{*}{0.483} \\
\hline Moderate and poorly & 95 & 87 & 8 & & 52 & 43 & \\
\hline \multicolumn{8}{|l|}{ Tumor size $(\mathrm{cm})$} \\
\hline$\leq 2$ & 50 & 42 & 8 & \multirow[t]{2}{*}{0.053} & 21 & 29 & \multirow[t]{2}{*}{0.061} \\
\hline$>2$ & 67 & 64 & 3 & & 41 & 26 & \\
\hline \multicolumn{8}{|l|}{ Lymph nodes } \\
\hline N0 & 43 & 35 & 8 & \multirow[t]{2}{*}{$0.018^{\mathrm{a}}$} & 17 & 26 & \multirow[t]{2}{*}{$0.035^{\mathrm{a}}$} \\
\hline N1-3 & 74 & 71 & 3 & & 45 & 29 & \\
\hline \multicolumn{8}{|l|}{ Pathological stage } \\
\hline I & 33 & 26 & 7 & \multirow[t]{2}{*}{$0.011^{\mathrm{a}}$} & 12 & 21 & \multirow[t]{2}{*}{$0.039^{\mathrm{a}}$} \\
\hline II-III & 84 & 80 & 4 & & 50 & 34 & \\
\hline \multicolumn{8}{|l|}{ Biological markers } \\
\hline ER & & & & \multirow{3}{*}{0.502} & & & \multirow{3}{*}{0.225} \\
\hline Positive & 82 & 73 & 9 & & 40 & 42 & \\
\hline Negative & 35 & 33 & 2 & & 22 & 13 & \\
\hline \multicolumn{8}{|l|}{ PR } \\
\hline Positive & 78 & 69 & 9 & \multirow[t]{2}{*}{0.332} & 38 & 40 & \multirow[t]{2}{*}{0.239} \\
\hline Negative & 39 & 37 & 2 & & 24 & 15 & \\
\hline HER-2/neu & & & & & & & \\
\hline Positive & 30 & 25 & 5 & 0.147 & 11 & 19 & 0.055 \\
\hline Negative & 87 & 81 & 6 & & 51 & 36 & \\
\hline
\end{tabular}

ER, estrogen receptor; PR, progesterone receptor; HER-2/neu, human epidermal growth factor receptor 2; IL-10, interleukin-10. ${ }^{\text {aP }}<0.05$.

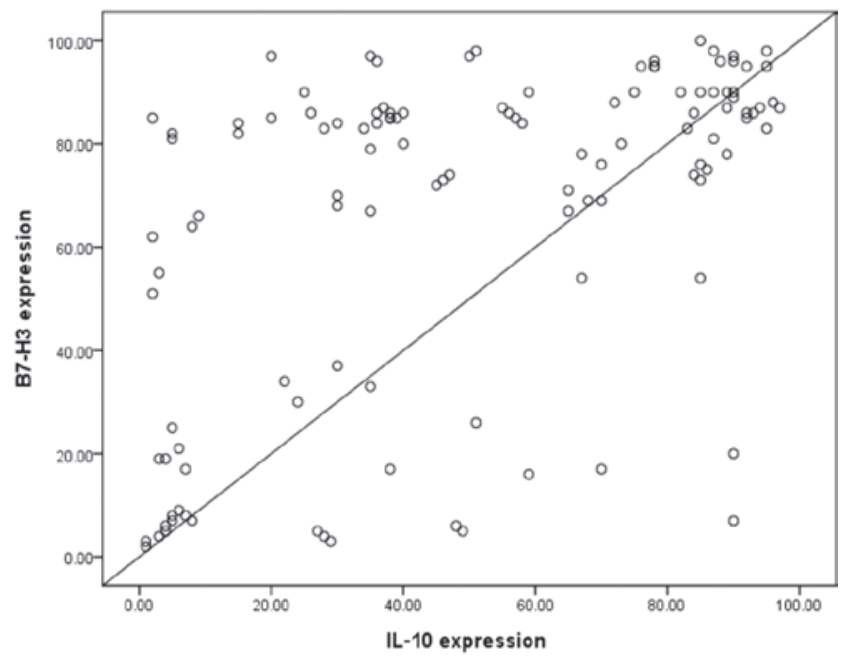

Figure 4. Correlation between B7-H3 and interleukin-10 (IL-10) expression. IL-10, interleukin-10. be of clinical significance in various types of cancer. In certain tumor types, high expression of B7-H3 has been linked to poor prognosis (17-19), whereas in other cancer types the opposite effect has been observed $(20,21)$. IL-10 is a pleiotropic cytokine produced by Th2 cells. Several studies have indicated that IL-10 is present in the tumor site and suggest that it mediates immunosuppression (13). A significant correlation between the expression of IL-10 and specific poor prognostic factors in human breast carcinomas has been observed $(14,15)$. The present study has examined B7-H3 and IL-10 expression in ductal and lobular breast cancer tissues. Immunohistochemical staining of B7-H3 and IL-10 in tumor cells revealed elevated cell surface and cytoplasmic staining. Our results have demonstrated that B7-H3 and IL-10 expression in breast cancer was associated with important prognostic factors associated with lymph node metastasis and tumor stage. B7-H3 expression was correlated with IL-10 in the tumor cells, which may be responsible for the clinical significance of B7-H3 expression. 
The mechanism accounting for the expression of B7-H3 in tumor cells remains unknown. However, expression of other inhibitory costimulatory factors has previously been described in various tumor cells. For example, a high expression of B7-H1, B7-H4 and ILT4 has been documented in certain malignant carcinomas $(17,22,23)$.

A common mechanism may exist in regulating the overexpression of the inhibitory factors in tumor cells. Studies have indicated that expression of some inhibitory costimulatory factors in tumor-related macrophages and DCs are upregulated by environmental IL-10 of cancer $(24,25)$. These observations suggest that the cytokine microenvironment induces expression of those inhibitors in tumor environmental cells. Expression of B7-H3 and IL-10 on breast cancer cells in the present study expands the information on immune inhibition.

The role of $\mathrm{B} 7-\mathrm{H} 3$ expression in malignant transformation or tumor progression has not been determined. B7 family members and their receptors are known to regulate antigen-specific immune response through inhibition of T-cell activation, cytokine secretion and the development of cytotoxicity (4-6). Extensive laboratory and histopathological data indicate that $\mathrm{T}$-cell immune reactivity is a favorable prognostic indicator in non-metastatic breast cancer and the suppression of cell-mediated immunity may be critically involved in breast cancer progress (12-14). B7-H3 protein has modest biological activities associated with the proliferation of $\mathrm{T}$ lymphocytes and enhanced IL-10 secretion (11). Expression of IL-10 in tumors has been associated with immunosuppression of a Th1 response and increased tumorigenicity (15). In addition, animals receiving xenotransplants of B16 melanoma cells demonstrate increased tumor growth following intralesional injection of IL-10 (26). These immunosuppressions may allow tumor cells to lodge and facilitate the growth of metastasis. Thus, it is likely that tumor B7-H3 contributes to breast carcinoma aggressiveness by promoting excessive IL-10 secretion, leading to a strong immunosuppressive effect.

In summary, our findings suggest for the first time that B7-H3 expression is correlated with IL-10 in tumor cells. This suggests a new mechanism by which breast carcinoma escapes immune defenses. Recognition of this new mechanism of tumor evasion is likely to necessitate a new approach to the design of B7-H3-based immunotherapy.

\section{Acknowledgements}

This study was partially sponsored by the Department of Science and Technology of Shandong Province.

\section{References}

1. Glass AG, Lacey JV, Carreon JD and Hoover RN: Breast cancer incidence, 1980-2006: combined roles of menopausal hormone therapy, screening mammography, and estrogen receptor status. J Natl Cancer Inst 99: 1152-1161, 2007.

2. Tirapu I, Huarte E, Guiducci C, et al: Low surface expression of B7-1 (CD80) is an immunoescape mechanism of colon carcinoma. Cancer Res 66: 2442-2450, 2006.

3. Ugurel S, Uhlig D, Pföhler C, Tilgen W, Schadendorf D and Reinhold U: Down-regulation of HLA class II and costimulatory CD86/B7-2 on circulating monocytes from melanoma patients. Cancer Immunol Immunother 53: 551-559, 2004.
4. Carreno BM and Collins M: The B7 family of ligands and its receptors: new pathways for costimulation and inhibition of immune responses. Annu Rev Immunol 20: 29-53, 2002.

5. Khoury SJ and Sayegh MH: The roles of the new negative T cell costimulatory pathways in regulating autoimmunity. Immunity 20: 529-538, 2004.

6. Prasad DV, Nguyen T, Li Z, Yang Y, Duong J, Wang Y and Dong C: Murine B7-H3 is a negative regulator of T cells. J Immunol 173: 2500-2506, 2004.

7. Suh WK, Gajewska BU, Okada H, et al: The B7 family member B7-H3 preferentially down-regulates $\mathrm{T}$ helper type 1-mediated immune responses. Nat Immunol 4: 899-906, 2003.

8. Ling V, Wu PW, Spaulding V, Kieleczawa J, Luxenberg D, Carreno BM and Collins M: Duplication of primate and rodent B7-H3 immunoglobulin V- and C-like domains: divergent history of functional redundancy and exon loss. Genomics 82: 365-377, 2003

9. Chapoval AI, Ni J, Lau JS, Wilcox RA, Flies DB, Liu D, Dong H, Sica GL, Zhu G, Tamada K and Chen L: B7-H3: a costimulatory molecule for $\mathrm{T}$ cell activation and IFN-gamma production. Nat Immunol 2: 269-274, 2001.

10. Greenwald RJ, Freeman GJ and Sharpe AH: The B7 family revisited. Annu Rev Immunol 23: 515-548, 2005.

11. Zhang GB, Chen YJ, Shi Q, Ma HB, Ge Y, Wang Q, Jiang Z, $\mathrm{Xu} \mathrm{Y}$ and Zhang XG: Human recombinant B7-H3 expressed in E. coli enhances T lymphocyte proliferation and IL-10 secretion in vitro. Acta Biochim Biophys Sin (Shanghai) 36: 430-436, 2004.

12. Moore KW, de Waal Malefyt R, Coffman RL and O'Garra A: Interleukin-10 and the interleukin-10 receptor. Annu Rev Immunol 19: 683-765, 2001.

13. Akdis CA and Blaser K: Mechanisms of interleukin-10-mediated immune suppression. Immunology 103: 131-136, 2001.

14. Woo SU, Bae JW, Yang JH, Kim JH, Nam SJ and Shin YK: Overexpression of interleukin-10 in sentinel lymph node with breast cancer. Ann Surg Oncol 14: 3268-3273, 2007.

15. Llanes-Fernández L, Alvarez-Goyanes RI, Arango-Prado Mdel C, et al: Relationship between IL-10 and tumor markers in breast cancer patients. Breast 15: 482-489, 2006.

16. Smith IE: New drugs for breast cancer. Lancet 360: 790-792, 2002.

17. Sun Y, Wang Y, Zhao J, Gu M, Giscombe R, Lefvert AK and Wang X: B7-H3 and B7-H4 expression in non-small-cell lung cancer. Lung Cancer 53: 143-151, 2006.

18. Crispen PL, Sheinin Y, Roth TJ, et al: Tumor cell and tumor vasculature expression of $\mathrm{B} 7-\mathrm{H} 3$ predict survival in clear cell renal cell carcinoma. Clin Cancer Res 14: 5150-5157, 2008.

19. Sun J, Chen LJ, Zhang GB, Jiang JT, Zhu M, Tan Y, Wang HT, Lu BF and Zhang XG: Clinical significance and regulation of the costimulatory molecule B7-H3 in human colorectal carcinoma. Cancer Immunol Immunother 59: 1163-1171, 2010.

20. Loos M, Hedderich DM, Ottenhausen M, Giese NA, Laschinger M, Esposito I, Kleeff $\mathrm{J}$ and Friess $\mathrm{H}$ : Expression of the costimulatory molecule $\mathrm{B} 7-\mathrm{H} 3$ is associated with prolonged survival in human pancreatic cancer. BMC Cancer 9: 463, 2009.

21. Wu CP, Jiang JT, Tan M, Zhu YB, Ji M, Xu KF, Zhao JM, Zhang GB and Zhang XG: Relationship between co-stimulatory molecule B7-H3 expression and gastric carcinoma histology and prognosis. World J Gastroenterol 12: 457-459, 2006.

22. Ohigashi Y, Sho M, Yamada Y, et al: Clinical significance of programmed death-1 ligand-1 and programmed death-1 ligand-2 expression in human esophageal cancer. Clin Cancer Res 11: 2947-2953, 2005.

23. Sun Y, Liu J, Gao P, Wang Y and Liu C: Expression of Ig-like transcript 4 inhibitory receptor in human non-small cell lung cancer. Chest 134: 783-788, 2008.

24. Kryczek I, Wei S, Zhu G, Myers L, Mottram P, Cheng P, Chen L, Coukos G and Zou W: Relationship between B7-H4, regulatory $\mathrm{T}$ cells, and patient outcome in human ovarian carcinoma. Cancer Res 67: 8900-8905, 2007.

25. Kryczek I, Zou L, Rodriguez P, et al: B7-H4 expression identifies a novel suppressive macrophage population in human ovarian carcinoma. J Exp Med 203: 871-881, 2006.

26. García-Hernández ML, Hernández-Pando R, Gariglio P and Berumen J: Interleukin-10 promotes B16-melanoma growth by inhibition of macrophage functions and induction of tumour and vascular cell proliferation. Immunology 105: 231-243, 2002. 